\title{
The influence of past experiences on future willingness to perform bystander cardiopulmonary resuscitation
}

\author{
Keng Sheng Chew ${ }^{1 *} \mathbb{D}$, Shazrina Ahmad Razali ${ }^{1}$, Shirly Siew Ling Wong ${ }^{2}$, Aisyah Azizul', Nurul Faizah Ismail ${ }^{1}$, \\ Sharoon Juliet Kun Chyee Ak Robert ${ }^{1}$ and Yegharaj A/L Jayaveeran ${ }^{1}$
}

\begin{abstract}
Background: The influence of past familial experiences of receiving cardiopulmonary resuscitation (CPR) and medical help in various cardiac arrest and nonfatal cardiac events toward willingness to "pay it forward" by helping the next cardiac arrest victim was explored.

Methods: Using a validated questionnaire, 6248 participants were asked to rate their willingness to perform bystander chest compression with mouth-to-mouth ventilation and chest compression-only CPR. Their past familial experiences of receiving cardiopulmonary resuscitation (CPR) and medical help in various cardiac arrest and nonfatal cardiac events were also recorded.

Results: Kruskal-Wallis test with post hoc Dunn's pairwise comparisons showed that the following were significantly more willing to perform CPR with mouth-to-mouth ventilation: familial experience of "nonfatal cardiac events" (mean rank $=447$ ) vs "out-of-hospital cardiac arrest with no CPR" (mean rank $=177$ ), $\mathrm{U}=35442.5, \mathrm{z}=-2.055, p=$ 0.04; "in-hospital cardiac arrest and successful CPR" (mean rank $=2955.79)$ vs "none of these experiences" (mean rank $=2468.38$ ), $U=111903, z=-2.60, p=0.01$; and "in-hospital cardiac arrest with successful CPR" (mean rank = 133.45) vs "out-of-hospital arrest with no CPR" (mean rank $=112.36$ ), $U=4135.5, z=-2.06, p=0.04$. For compression-only CPR, Kruskal-Wallis test with multiple runs of Mann-Whitney $U$ tests showed that "nonfatal cardiac events" group was statistically higher than the group with "none of these experiences" (mean rank $=3061.43$ vs 2859.91), $U=1194658, z=-2.588, p=0.01$. The groups of "in-hospital cardiac arrest with successful CPR" and "inhospital cardiac arrest with transient return of spontaneous circulation" were the most willing groups to perform compression-only CPR.
\end{abstract}

Conclusion: Prior familial experiences of receiving CPR and medical help, particularly among those with successful outcomes in a hospital setting, seem to increase the willingness to perform bystander CPR.

Keywords: Bystander cardiopulmonary resuscitation, Pay-it-forward, Cardiac arrest

\section{Introduction}

As $80 \%$ of out-of-hospital cardiac arrest (OHCA) cases happened at home [1] as a result of cardiovascular diseases [2], it is imperative to educate the general public on the skills of bystander cardiopulmonary resuscitation (CPR) [3]. Studies have shown that bystander CPR improves the chance of survival of OHCA by up to two

\footnotetext{
* Correspondence: kschew@unimas.my

${ }^{1}$ Faculty of Medicine of Health Sciences, Universiti Malaysia Sarawak, 94300

Kota Samarahan, Sarawak, Malaysia

Full list of author information is available at the end of the article
}

to three times [4]. Despite that, the rate of bystander $\mathrm{CPR}$ has not been as encouraging as we would like it to be $[5-7]$.

A number of studies had been conducted to identify factors influencing the willingness of bystanders to perform CPR [6-14]. These factors can generally be divided into two broad categories, i.e., (1) bystander factors and the (2) victim factors. Bystander factors that increase the willingness to perform bystander CPR include bystanders' prior CPR training $[6,7,10]$, bystander's educational and income level [10-12], and the 
bystanders' emotional state at the time of the incident $[10,13]$. Victim factors that increase the chance of having bystander CPR performed include the familiarity and the relationship of the victim to the bystander $[8,9,14]$ : a child victim [8] and the perceived cleanliness of the victim [9]. One factor that is conspicuously less explored, however, is the influence of the bystanders' past familial experiences of receiving CPR and medical help in various IHCA or OHCA conditions and nonfatal cardiac events on his or her future willingness to perform bystander CPR.

"Pay-it-forward" is an expression in which a recipient of an act of kindness reciprocates by repaying this kind act to someone else rather than to the original benefactor [15]. This concept was crisply captured by author Lily Hardy Hammond as early as 1916, when she famously wrote in her book, In the Garden of Delight [16], "You don't pay love back; you pay it forward." Undergirding the motivation to pay it forward is the feeling of indebtedness for the help that one has received [17]. In the context of disasters, Atsumi (2014) and Daimon (2018) demonstrated that survivors of the Great East Japan Earthquake in 2011 who had received help were more likely to render help by volunteering to help out in future disasters [17, 18]. According to Atsumi (2014), these survivors seemed to be relieved by volunteering to assist in other disaster events [17].

We are not certain if help received in a prior cardiac arrest event may play an important role in influencing bystanders to perform CPR (similar to the "pay-it-forward" mechanism discussed above). Hence, we embarked on this study with the primary objective of exploring whether prior familial experience with cardiac arrests (with or without bystander CPR) or nonfatal cardiac events has a significant effect in increasing the willingness to perform bystander CPR. The secondary objectives of this study are to explore the influence of four personal characteristics (i.e., gender, involvement in a medical nongovernmental organizations (NGOs) such as Red Crescent Malaysia, St. John Ambulance Malaysia, Civil Defence, etc., their prior CPR training, and their prior experience of administering bystander CPR toward their willingness to perform bystander CPR.

\section{Materials and methods \\ Participants}

The respondents of this survey were the adult participants of a mass CPR event held on 20 September 2017 in Universiti Malaysia Sarawak (UNIMAS), which is a public university located in the state of Sarawak, Malaysia [19]. Convenience sampling was applied. Prior informed consent was obtained from the participants before starting this survey. The participants were assured that no personal data such as their names and national identification numbers or passport numbers would be collected. Approval to conduct this study was obtained from institutional research ethics board of UNIMAS (reference no: UNIMAS/NC-21.02/03-02 Jld.3 [94]).

\section{Materials}

A self-administered questionnaire comprises of three parts, i.e., the demographic data (Part A), public knowledge of CPR (Part B), and general public attitudes toward CPR (Part C) was used in this survey. The draft of the questionnaire was first constructed by a panel of experts consisting of emergency physicians and trainers of basic life support. Validation of the questionnaire was then performed by ten clinical lecturers from Faculty of Medicine and Health Science, UNIMAS, in order to determine its internal consistency as well as its interrater reliability. The Cronbach alpha of this questionnaire is 0.93 indicating good internal consistency of the items. The intra-class correlation coefficient is 0.93 , indicating good inter-rater reliability.

With regard to past familial (or even personal) experiences with nonfatal cardiac events and cardiac arrest, the participants were asked "Have you or any of your family member/loved ones had the following incident before? (1) "Nonfatal heart attack," i.e., heart attack before but not collapsed; (2) "OHCA with successful CPR," i.e., collapsed at home and had successful bystander CPR done outside of hospital and subsequently admitted to hospital; (3) "OHCA with unsuccessful CPR," i.e., collapsed at home, had bystander CPR done but unsuccessful; (4) "OHCA with no CPR," i.e., collapsed at home with no CPR done; (5) "in-hospital cardiac arrest or IHCA with transient ROSC," i.e., collapsed in hospital, had CPR done with transient return of spontaneous circulation or ROSC but subsequently passed away in hospital; (6) "had successful CPR done in hospital and subsequently discharged alive" (IHCA with successful CPR); (7) "had unsuccessful CPR done in hospital" (IHCA with unsuccessful CPR); and (8) "none of these experiences or not applicable." The willingness to perform both chest compression with mouth-to-mouth ventilation (CC + MTM) as well as chest compression-only (CC only) CPR was captured on a Likert scale from " 1 " (least willing) to 10 ("most willing").

\section{Procedure}

As mentioned, this anonymous, volitional survey was conducted in conjunction with the 1-day mass CPR educational program which was held from 8:00 am to 8:00 pm (ten sessions) on 20 September 2017 in UNIMAS [19]. While waiting for their practice sessions, the questionnaire forms were distributed to the participants. The authors of this paper and their research assistants were 
present on that day to respond to any specific query from the participants with regard to the questionnaire.

\section{Results}

A total of 6248 participants participated in the survey. Out of these, 4366 participants (69.8\%) were female, and 1871 (29.9\%) participants were male (11 participants did not reveal their gender). In terms of their age groups, majority of the participants (3187 or 51\%) were below the age of 20 years old, followed by those between 21 to 30 years old (2336 or $37.4 \%$ ), and 469 participants $(7.5 \%)$ were between 31 to 40 years old. Only 11 participants $(0.2 \%)$ were above 60 years old (21 missing data). (See Table 1 for the details of the demographic data of the participants)

Nonparametric tests were applied in this survey as the normality of the distribution of all data could not be assumed, with Shapiro-Wilk test $p<0.05$, skewness $\mathrm{z}$ value of -2.90 (standard error or $\mathrm{SE}=0.05$ ), and kurtosis $\mathrm{z}$ value of $-4.90(\mathrm{SE}=0.12)$ for male participants on their willingness to perform CC only, and for female participants, the skewness and kurtosis $\mathrm{z}$ values are $-0.45(\mathrm{SE}=0.04)$ and $-5.31(\mathrm{SE}=0.08)$, respectively. Similarly, for willingness to perform CC + MTM, skewness and kurtosis $\mathrm{z}$ values are $-12.5(\mathrm{SE}=0.06)$ and $-3.05(\mathrm{SE}=0.11)$, respectively, for male participants; and $-18.03(\mathrm{SE}=0.04)$ and $-2.95(0.07)$, respectively, for female participants and Shapiro-Wilk test $p<0.05$.

Overall, the willingness to perform CC only was shown to be higher with median score of 7.00 (inter-quartile range, IQR $5.00,9.00$ ) as compared to the willingness to perform CC + MTM with the median score of 5.00 (IQR $5.00,8.00)$. Mann-Whitney $U$ tests were performed to analyze the association between willingness to perform both CC + MTM and CC only with four personal characteristics of the participants, i.e., (1) their gender, (2) involvement in a medical nongovernmental organizations (NGOs) such as Red Crescent Malaysia, St. John Ambulance Malaysia, Civil Defence, etc., (3) their prior CPR training, and (4) their prior experience of administering bystander CPR toward their willingness to perform bystander CPR. Generally, male gender, participants who were members of medical NGOs, participants who had prior CPR training, and participants who had previous experience of administering bystander CPR reported to be significantly more willing to administer both types of bystander CPR. The details of these results are tabulated in Tables 2 and 3.

With regard to the influence of past family experiences with cardiac arrest and nonfatal cardiac events on the willingness to perform CC + MTM, Kruskal-Wallis test showed significant differences $(p<0.001)$ between the mean ranks of at least one pair of the groups, with $\mathrm{H}(7)=$ 30.21. Post hoc Dunn's pairwise comparisons were carried out for the 28 pairs of groups. Significant difference $(p<$
Table 1 Descriptive data of participants

\begin{tabular}{|c|c|c|}
\hline Variables & $\begin{array}{l}\text { Frequency } \\
(n=6248)\end{array}$ & $\%$ \\
\hline \multicolumn{3}{|l|}{ Gender } \\
\hline Male & 1871 & 29.9 \\
\hline Female & 4366 & 69.9 \\
\hline Missing data & 11 & 0.2 \\
\hline \multicolumn{3}{|l|}{ Age group } \\
\hline below 20 years old & 3187 & 51.0 \\
\hline $21-30$ years old & 2336 & 37.4 \\
\hline $31-40$ years old & 469 & 7.5 \\
\hline $41-50$ years old & 157 & 2.5 \\
\hline $51-60$ years old & 67 & 1.1 \\
\hline above 60 years old & 11 & 0.2 \\
\hline Missing data & 21 & 0.3 \\
\hline \multicolumn{3}{|l|}{ Occupation } \\
\hline Students & 4770 & 76.3 \\
\hline Professional/technical works & 402 & 6.4 \\
\hline Administrative and clerical work & 138 & 2.2 \\
\hline Armed forces & 15 & 0.2 \\
\hline Elementary occupations & 5 & 0.1 \\
\hline Plant and machine operators & 4 & 0.1 \\
\hline Service and sales sector & 62 & 1.0 \\
\hline Skilled agricultural & 37 & 0.6 \\
\hline Self-employed & 38 & 0.6 \\
\hline Retired & 15 & 0.2 \\
\hline Unemployed & 165 & 2.6 \\
\hline Missing data & 597 & 9.7 \\
\hline \multicolumn{3}{|l|}{ Highest education level } \\
\hline No formal education & 12 & 0.2 \\
\hline Primary & 91 & 1.5 \\
\hline Secondary & 1824 & 29.2 \\
\hline Post-secondary (diploma, certificate, etc.) & 1794 & 28.7 \\
\hline Tertiary & 2527 & 40.4 \\
\hline \multicolumn{3}{|c|}{ Member of any medical nongovernmental organizations (NGO)? } \\
\hline Yes & 697 & 11.2 \\
\hline No & 5420 & 86.7 \\
\hline Missing data & 131 & 2.1 \\
\hline
\end{tabular}

0.001), adjusted using the Bonferroni correction, was found between the group with nonfatal cardiac events versus the group who had "none of these experiences" $(p<$ 0.001). Multiple runs of Mann-Whitney U tests subsequently performed for further pairwise comparisons were consistent with this finding. In particular, the score for the group of nonfatal cardiac events (mean rank $=447$ ) was statistically higher than for the group of OHCA with no $\mathrm{CPR}$ (mean rank $=177$ ), $\mathrm{U}=35442.5, \mathrm{z}=-2.055, p=$ 
Table 2 Association of independent variables with the willingness to perform bystander CC + MTM $(n=6248)$

\begin{tabular}{|c|c|c|c|c|}
\hline & $\begin{array}{l}\text { Median } \\
\text { (Inter-quartile range 25th percentile, } \\
\text { 75th percentile) }\end{array}$ & Mean rank & U-statistics & $p$ value \\
\hline Male & $\begin{array}{l}6.00 \\
(5.00,8.00)\end{array}$ & 3177.82 & 2999505 & $p<0.001$ \\
\hline Female & $\begin{array}{l}5.00 \\
(5.00,7.00)\end{array}$ & 2775.99 & & \\
\hline $\begin{array}{l}\text { Member of a medical uniformed NGO such as } \\
\text { St. John's ambulance, red crescent, etc. }\end{array}$ & $\begin{array}{l}6.00 \\
(5.00,8.00)\end{array}$ & 3029.54 & 1517177.5 & $p=0.002$ \\
\hline Not a member of any medical uniformed NGO & $\begin{array}{l}5.00 \\
(5.00,8.00)\end{array}$ & 2817.13 & & \\
\hline With previous experience of administering CPR & $\begin{array}{l}6.00 \\
(5.00,8.00)\end{array}$ & 2877.42 & 1205596 & $p<0.001$ \\
\hline Without previous experience of administering CPR & $\begin{array}{l}5.00 \\
(5.00,7.00)\end{array}$ & 2610.13 & & \\
\hline With CPR training & $\begin{array}{l}6.00 \\
(5.00,8.00)\end{array}$ & 2974.04 & 4039339 & $p<0.001$ \\
\hline Without CPR training & $\begin{array}{l}5.00 \\
(5.00,7.00)\end{array}$ & 2831.39 & & \\
\hline
\end{tabular}

Note: all inferential statistics were performed using Mann-Whitney $U$ test

0.04. The group of IHCA with successful CPR (mean rank $=2955.79$ ) was statistically higher than the group with "none of these experiences" (mean rank $=2468.38$ ), $\mathrm{U}=$ $111903, \mathrm{z}=-2.60, p=0.01$. Similarly, the group of IHCA with successful CPR (mean rank $=133.45$ ) was also statistically higher than the group OHCA with no CPR (mean rank = 112.36), $\mathrm{U}=4135.5, \mathrm{z}=-2.06, p=0.04$.

With regard to the influence of past family experiences with cardiac arrest and nonfatal cardiac events on the willingness to perform $\mathrm{CC}$ only, Kruskal-Wallis test showed significant differences $(p=0.001)$ between the mean ranks of at least one pair of the groups, with $\mathrm{H}(7)$ $=25.34$. However, the post hoc Dunn's pairwise comparisons adjusted using Bonferroni correction on the 28 pairs of groups were not able to detect which pair(s) of groups has or have significant differences. Multiple runs of Mann-Whitney $U$ tests subsequently performed for further pairwise comparisons found that the scores for the group of nonfatal cardiac events was statistically higher than the group with "none of these experiences" (mean rank $=3061.43$ vs 2859.91), $\mathrm{U}=$ $1194658, \mathrm{z}=-2.588, p=0.01$. The group of IHCA with successful CPR, however, appears to be most willing to perform CC only as the score for this group was significantly higher when compared to the following four groups: (1) with the group of nonfatal cardiac events (mean rank =

Table 3 Association of independent variables with the willingness to perform bystander CC only $(n=6248)$

\begin{tabular}{|c|c|c|c|c|}
\hline & $\begin{array}{l}\text { Median } \\
\text { (Inter-quartile range 25th percentile, } 75 \text { th percentile) }\end{array}$ & Mean rank & U-statistics & $p$ value \\
\hline Male & $\begin{array}{l}7.00 \\
(5.00,9.00)\end{array}$ & 3191.08 & 3949536 & $p=0.04$ \\
\hline Female & $\begin{array}{l}7.00 \\
(7.00,8.00)\end{array}$ & 3088.11 & & \\
\hline $\begin{array}{l}\text { Member of a medical uniformed NGO such as } \\
\text { St. John's ambulance, red crescent, etc. }\end{array}$ & $\begin{array}{l}7.00 \\
(5.00,9.00)\end{array}$ & 3195.03 & 1794058.5 & $p=0.03$ \\
\hline Not a member of any medical uniformed NGO & $\begin{array}{l}7.00 \\
(7.00,9.00)\end{array}$ & 3041.51 & & \\
\hline With previous experience of administering CPR & $\begin{array}{l}8.00 \\
(5.00,8.00)\end{array}$ & 3056.35 & 13368.22 & $p<0.001$ \\
\hline Without previous experience of administering CPR & $\begin{array}{l}7.00 \\
(5.00,9.00)\end{array}$ & 2729.54 & & \\
\hline With CPR training & $\begin{array}{l}7.00 \\
(5.00,9.00)\end{array}$ & 3174.20 & 4039339 & $p<0.001$ \\
\hline Without CPR training & $\begin{array}{l}7.00 \\
(5.00,8.25)\end{array}$ & 2968.37 & & \\
\hline
\end{tabular}


313.91 vs 269.18), $\mathrm{U}=12041.5, \mathrm{z}=-2.076, p=0.038$; (2) with the group of OHCA with unsuccessful CPR (mean rank $=59.21$ vs 42.33$), \mathrm{U}=872.5, \mathrm{z}=-2.878, p=0.004$; (3) with the group of OHCA with successful CPR (mean rank = 60.18 vs 47.66$), \mathrm{U}=1110.5, \mathrm{z}=-2.101, p=0.036$; (4) with the group of OHCA with no CPR (mean rank $=146.78$ vs 118.93), $\mathrm{U}=4379, \mathrm{z}=-2.619, p=0.009$; and (5) with the group with "none of these experiences" (mean rank = 3277.49 vs 2655.61$), \mathrm{U}=119033, \mathrm{z}=-3.119, p=0.002$.

Similarly, the score for the group of IHCA with CPR and transient ROSC was also significantly higher than that for the following groups: (1) with the group of OHCA with unsuccessful CPR (mean rank $=71.00$ vs 43.41), $\mathrm{U}=$ 1360.0, $\mathrm{z}=-2.564, p=0.01$; (2) with the group of OHCA with no CPR (mean rank $=154.18$ vs 131.52 ), $\mathrm{U}=6784.5$, $\mathrm{z}=-2.204, p=0.03$; and (3) with the group with "none of these experiences" (mean rank $=3140.19$ vs 2668.00), $\mathrm{U}=$ 184264.0, $\mathrm{z}=-2.822, p=0.005$.

With regard to the influence of the participants' educational level on their willingness to perform CC + MTM, Kruskal-Wallis test showed significant differences $(p=$ 0.028 ) between the mean ranks of at least one pair of the groups, with $\mathrm{H}(4)=10.855$. Post hoc Dunn's pairwise comparisons were carried out for the ten pairs of groups. Significant difference $(p=0.031)$, adjusted using the Bonferroni correction, found that participants with tertiary education (mean rank 2983.78) were significantly more willing than participants with post-secondary education (mean rank 2828.56), $\mathrm{U}=155.22, \mathrm{z}=-2.96, p=0.031$. Similarly, with regard to the influence of the participants' educational level on their willingness to perform CC only, Kruskal-Wallis test showed significant differences $(p<$ 0.001 ) between the mean ranks of at least one pair of the groups, with $\mathrm{H}(4)=32.587$. Post hoc Dunn's pairwise comparisons were carried out for the ten pairs of groups. Significant difference $(p=0.031)$, adjusted using the Bonferroni correction, was found between the group with primary education (mean rank $=2447.47$ ) vs postsecondary education (mean rank $=3173.15)(p=0.002)$; between primary education (mean rank $=2447.47$ ) vs tertiary education (mean rank $=3216.40)(p=0.001)$; between secondary education (mean rank $=2985.43$ ) vs postsecondary education $($ mean rank $=3173.15)(p=0.016)$; and between secondary education (mean rank $=2985.43$ ) and tertiary education (mean rank $=3216.40)(p<0.001)$.

\section{Discussion}

Our results show that participants with past familial experiences of IHCA with successful CPR or IHCA with CPR and transient ROSC as well as nonfatal cardiac events (did not require CPR) were significantly more willing to perform bystander CPR (both CC + MTM and CC only).

This significant increase in willingness to perform bystander CPR could probably be explained from psychological and sociological points of view. In their arousal: cost-reward model, Dovidio et al. (1991) conceptualized the idea that when one becomes aware that a victim is suffering in an emergency situation, this arouses an emotionally unpleasant experience, and the way to relieve this unpleasant emotion is by rendering help to the victim. This also explains the importance of creating awareness among bystanders that cardiac arrest is an emergency situation that requires prompt intervention [20].

Piliavin and Charng (1990) also show that people are more willing to help after a disaster has occurred to them [21]. This finding is consistent with Blau's homo economicus theory of social exchange [22]. According to Blau (1960), a person who has received help from others often feels obligated to reciprocate. In this regard, "paying it forward" (by helping another cardiac arrest victim) is postulated as a mechanism to relieve such obligation. Similarly, according to the "warm-glow giving" theory by Andreoni (1990), people volunteer because of the sense of joy and personal satisfaction for having helped someone [23]. In this regard, participants who had been helped by others before are more willing to volunteer an altruistic act such as bystander CPR for the next victim for the sense of warm glow that they can derive [23].

Surprisingly, however, familial experiences of OHCA with CPR (even among those with the successful outcome of having the victim revived and subsequently brought to the hospital for further management) did not seem to significantly increase the willingness to perform bystander CPR. The reason for this could not be ascertained, but it could probably be due to the fact that as all victims who had been successfully revived (i.e., achieved ROCS) in an out-of-hospital setting were subsequently brought in to the hospital. Hence, the participants might have attributed to the success (or failure) of the eventual outcomes of resuscitation to the efforts made by hospital staff rather than that of the bystanders.

In this study, we found that male gender as well as educational level seems to have a significant influence on the willingness to perform bystander CPR. Those who have higher educational levels seem to be more willing than those with lower educational level to perform bystander $\mathrm{CPR}$. These findings are consistent with a number of previous studies on volunteerism [24,25]; although a recent literature review by Haski-Leventhal (2009) found that except for educational level which has been consistently found to be related to increased willingness to volunteer, studies on other sociodemographic factors such as income and gender had led to mixed results [26]. In this study, those who have been trained in CPR or had prior experience as a member of a medical NGO or had administered bystander CPR were also significantly more willing to perform bystander CPR. As demonstrated in a previous study by Shotland and Heinold (1985), logically those who had 
been trained would be more competent and, hence, more willing to help [27]. Having such a competent bystander around is also important in the sense that his or her mere presence has been demonstrated in previous studies to encourage and empower other less competent bystanders to offer some form help [28-31].

There are a number of pertinent limitations in this study. First, as OHCA victims who had been successfully resuscitated through bystander CPR would eventually be transferred to the hospitals, the participants might have attributed the success (or failure) of CPR based on the eventual outcomes from the hospital particularly if the victim collapsed again in the hospital. Hence, it could be that the eventual outcomes from the hospitals that might influence the willingness of them to render bystander CPR rather than the initial outcomes from bystander CPR in an out-of-hospital setting. Perhaps, a future study could be conducted with more specific subcategories, such as asking the participants on their willingness to perform bystander CPR based on the successful outcome of bystander CPR that their family members received in the out-of-hospital setting per se (regardless of the eventual outcome in the hospital). Secondly, the competency and knowledge of the participants with regard to the prompt need of bystander CPR was not ascertained. This could have affected their willingness to perform bystander CPR even if they had family members whom previously had received bystander CPR. As this study was conducted in a university setting and as demonstrated in the demographic data of the participants, majority of the participants were university students from the younger age brackets. These would have skewed the responses obtained, and hence, the results might not be generalizable to another population. Finally, although a link has been drawn between the results of this study with the "paying-it-forward" mechanism as the possible explanation, this remains a postulation, at best. Perhaps, future study could be conducted to delve into the various reasons on why a bystander would or would not perform bystander CPR, including the possible psychological reasons such as the "payingit-forward" mechanism discussed above.

\section{Conclusion}

This study suggests that prior familial experiences of receiving CPR, particularly among those with successful outcomes in a hospital setting, seem to increase the willingness to "pay it forward" by volunteering to perform bystander CPR on the next victim. Male participants as well as those who have been trained or administered bystander CPR before or who are members of medical NGOs also seem to be more willing to perform bystander CPR.

\section{Acknowledgements}

The authors would like to thank Dr. Nariman Singmamae and Mr. Dev Nath Kaushal for their input during the initial conception of the research design.

\section{Authors' contributions}

All authors (KSC, SAR, SSLW, AA, NFI, SJR, and YJ) were involved in the initial conception of the study design. SAR, SSLW, AA, NFI, SJR, and YJ were involved in collecting data; all authors (KSC, SAR, SSLW, AA, NFI, SJR, and YJ) were involved in the data analysis. KSC were involved in writing up the draft of the manuscript to be approved by all authors. All authors (KSC, SAR, SSLW, $\mathrm{AA}, \mathrm{NFI}, \mathrm{SJR}$, and $\mathrm{YJ}$ ) approved the final draft of the manuscript.

\section{Funding}

Not applicable.

\section{Availability of data and materials}

The dataset is not available publicly; however, it may be requested from the corresponding author upon reasonable request.

\section{Ethics approval and consent to participate}

Ethical approval was obtained from the Medical Research and Ethics Committee, Universiti Malaysia Sarawak (UNIMAS), ref. no: UNIMAS/NC-21.02/ 03-02 Jld.3 [94]). Informed consent was obtained from all participants prior to their participation in this study.

\section{Consent for publication}

Participants were informed that his or her data would be used anonymously for subsequent analysis, presentation, and publication.

\section{Competing interests}

The authors declare that they have no competing interests.

\section{Author details}

${ }^{1}$ Faculty of Medicine of Health Sciences, Universiti Malaysia Sarawak, 94300 Kota Samarahan, Sarawak, Malaysia. ${ }^{2}$ Faculty of Economics and Business, Universiti Malaysia Sarawak, 94300 Kota Samarahan, Sarawak, Malaysia.

Received: 25 July 2019 Accepted: 8 November 2019

Published online: 12 December 2019

\section{References}

1. Berg RA, Hemphill R, Abella BS, Aufderheide TP, Cave DM, Hazinski MF, et al. Part 5: adult basic life support: 2010 American Heart Association Guidelines for Cardiopulmonary Resuscitation and Emergency Cardiovascular Care. Circulation. 2010;122(18 Suppl 3):S685-705.

2. Litwin PE, Eisenberg MS, Hallstrom AP, Cummins RO. The location of collapse and its effect on survival from cardiac arrest. Annals of emergency medicine. 1987;16(7):787-91.

3. Jacobs I, Nadkarni V, Bahr J, Berg RA, Billi JE, Bossaert L, et al. Cardiac arrest and cardiopulmonary resuscitation outcome reports: update and simplification of the Utstein templates for resuscitation registries: a statement for healthcare professionals from a task force of the International Liaison Committee on Resuscitation (American Heart Association, European Resuscitation Council, Australian Resuscitation Council, New Zealand Resuscitation Council, Heart and Stroke Foundation of Canada, InterAmerican Heart Foundation, Resuscitation Councils of Southern Africa). Circulation. 2004;110(21):3385-97.

4. Weisfeldt ML, Everson-Stewart S, Sitlani C, Rea T, Aufderheide TP, Atkins DL, et al. Ventricular tachyarrhythmias after cardiac arrest in public versus at home. New England J Med. 2011;364(4):313-21.

5. American Heart Association (AHA) 2018. CPR Facts and Stats. Retrieved from: https://cpr.heart.org/AHAECC/CPRAndECC/ AboutCPRECC/CPRFactsAndStats/UCM_475748_CPR-Facts-and-Stats.jsp. Accessed 1 Sept 2018

6. Coons SJ, Guy MC. Performing bystander CPR for sudden cardiac arrest: behavioral intentions among the general adult population in Arizona. Resuscitation. 2009;80(3):334-40.

7. Johnston TC, Clark MJ, Dingle GA, FitzGerald G. Factors influencing Queenslanders' willingness to perform bystander cardiopulmonary resuscitation. Resuscitation. 2003;56(1):67-75. 
8. Horowitz BZ, Matheny L. Health care professionals' willingness to do mouthto-mouth resuscitation. West J Med. 1997;167(6):392-7.

9. Chew KS, Yazid MN. The willingness of final year medical and dental students to perform bystander cardiopulmonary resuscitation in an Asian community. Int J Emergency Med. 2008;1(4):301-9.

10. Swor R, Khan I, Domeier R, Honeycutt L, Chu K, Compton S. CPR training and CPR performance: do CPR-trained bystanders perform CPR? Acad Emerg Med. 2006;13(6):596-601.

11. Vaillancourt C, Lui A, De Maio VJ, Wells GA, Stiell IG. Socioeconomic status influences bystander CPR and survival rates for out-of-hospital cardiac arrest victims. Resuscitation. 2008;79(3):417-23.

12. Sasson C, Cudnik MT, Nassel A, Semple H, Magid DJ, Sayre M, et al. Identifying high-risk geographic areas for cardiac arrest using three methods for cluster analysis. Acad Emerg Med. 2012;19(2):139-46.

13. Sasson C, Haukoos JS, Bond C, Rabe M, Colbert SH, King R, et al. Barriers and facilitators to learning and performing cardiopulmonary resuscitation in neighborhoods with low bystander cardiopulmonary resuscitation prevalence and high rates of cardiac arrest in Columbus, $\mathrm{OH}$. Circ Cardiovasc Qual Outcomes. 2013;6(5):550-8.

14. Jelinek GA, Gennat H, Celenza T, O'Brien D, Jacobs I, Lynch D. Community attitudes towards performing cardiopulmonary resuscitation in Western Australia. Resuscitation. 2001:51(3):239-46.

15. Dictionary.com. What does pay it forward mean? Available at URL: https:// www.dictionary.com/e/pop-culture/pay-it-forward/ Accessed 17 June 2019

16. Hammond LH. In the garden of delight. 1916. in: Internet Archive. Available at URL: http://books.google.com/books?id=riweAAAAMAAJ.

17. Atsumi T. Relaying support in disaster-affected areas: the social implications of a 'pay-it-forward' network. Disasters. 2014;38(Suppl 2):S144-56.

18. Daimon H, Atsumi T. "Pay it forward" and altruistic responses to disasters in Japan: latent class analysis of support following the 2011 Tohoku earthquake. VOLUNTAS. 2018;29(1):119-32.

19. News Desk (2017, October 5). UNIMAS creates new CPR record. New Sarawak Tribune. Available at URL: https:/www.newsarawaktribune.com.my/ news/unimas-creates-new-cpr-record/ Accessed 13 Jan 2019

20. Dovidio JF, Piliavin JA, Gaertner SL, Schroeder DA, Clark lii RD. The arousal: cost-reward model and the process of intervention: a review of the evidence. In: Prosocial behavior. Review of personality and social psychology, Vol. 12. Thousand Oaks, CA, US: Sage Publications, Inc; 1991. p. 86-118.

21. Piliavin JA, Charng H-W. Altruism: a review of recent theory and research. Annual Rev Sociol. 1990;16(1):27-65.

22. Blau PM. Exchange and power in social life. New York: Wiley; 1967.

23. Andreoni J. Impure altruism and donations to public goods: a theory of warm-glow giving. Econ J. 1990;100(401):464-77.

24. Pearce JL. Volunteers: the organizational behavior of unpaid workers. 1st ed. New Yorkd: Routledge; 1993

25. Wilson J, Musick M. Who cares? Toward an integrated theory of volunteer work. Am Sociol Rev. 1997;62(5):694-713.

26. Haski-Leventhal D. Altruism and volunteerism: the perceptions of altruism in four disciplines and their impact on the study of volunteerism. J Theor Soc Behav. 2009;39(3):271-99.

27. Shotland RL, Heinold WD. Bystander response to arterial bleeding: helping skills, the decision-making process, and differentiating the helping response. J Pers Soc Psychol. 1985;49(2):347-56.

28. Horowitz IA. The effect of group norms on bystander intervention. J Soc Psychol. 1971;83(2):265-73.

29. Fischer P, Greitemeyer T, Pollozek F, Frey D. The unresponsive bystander: are bystanders more responsive in dangerous emergencies? Eur J Soc Psychol. 2006;36(2):267-78.

30. van den Bos K, Müller PA, van Bussel AAL. Helping to overcome intervention inertia in bystander's dilemmas: behavioral disinhibition can improve the greater good. J Exp Soc Psychol. 2009;45(4):873-8.

31. Cramer RE, McMaster MR, Bartell PA, Dragna M. Subject competence and minimization of the bystander effect. J Appl Soc Psychol. 1988; 18(13):1133-48

\section{Publisher's Note}

Springer Nature remains neutral with regard to jurisdictional claims in published maps and institutional affiliations.

\section{Ready to submit your research? Choose BMC and benefit from:}

- fast, convenient online submission

- thorough peer review by experienced researchers in your field

- rapid publication on acceptance

- support for research data, including large and complex data types

- gold Open Access which fosters wider collaboration and increased citations

- maximum visibility for your research: over $100 \mathrm{M}$ website views per year

At $\mathrm{BMC}$, research is always in progress.

Learn more biomedcentral.com/submissions 